\title{
NOREPINEPHRINE, DOPAMINE AND SEROTONIN IN EXPERIMENTAL SPINAL CORD TRAUMA: CURRENT STATUS*
}

\author{
By Robert A. Brodner, M.D. and George J. Dohrmann, M.D., Ph.D. \\ Department of Neurosurgery, Mount Sinai School of Medicine, New York, N.Y. Iooz9 and \\ Section of Neurosurgery, Department of Surgery, Yale University School of Medicine, New \\ Haven, Connecticut, U.S.A.
}

Abstract. This is a review on norepinephrine, dopamine and serotonin with regard to their action following spinal cord injuries which reveals the controversies on this subject.

Key words: Norepinephrine; dopamine; serotonin.

\section{Introduction}

THE role of neurochemical factors in the pathophysiology of experimental spinal cord trauma has been widely studied, and recently considerable attention has been focused on the biogenic amines (Dohrmann, 1972; Osterholm, 1974). Much of the available data is inconsistent, with conflicting results being reported both in the basic pathophysiological studies as well as in the treatment studies.

The importance of a potentially reversible pathochemical substrate in spinal cord injury and its possible therapeutic implications are clear. The continued controversy concerning the role of the monoamines, norepinephrine, dopamine and serotonin, in spinal cord trauma has clouded the data and has rendered interpretation most difficult. In this paper, the function of monoamines in neural trauma is reviewed and the data discussed.

\section{Norepinephrine}

Osterholm and Mathews (1972) initially engendered much interest in the pathophysiology of spinal cord trauma by the demonstration of catecholamine alterations that may be responsible for destructive processes in traumatic paraplegia and also be amenable to therapeutic intervention. Using a $500 \mathrm{~g}-\mathrm{cm}$ contusion, they found significant norepinephrine elevation in the injured cat spinal cord within the first 4 hours after trauma and correlated this with the presence of haemorrhagic necrosis of the central grey matter, the most prominent early pathological finding following spinal cord injury. Osterholm and Mathews (I972) proposed that toxic quantities of norepinephrine are released into the cord tissue after contusion resulting in vasoconstriction, ischemia and tissue necrosis with resultant vascular rupture and haemorrhage. The validity of this hypothesis was substantiated in part by the production of large central haemorrhages 2 hours after intraspinal norepinephrine injection (Osterholm and Mathews, I972). In addition, the effects of several anti-norepinephrine agents on the contused feline spinal cord were studied, and all were found to have distinct protective action (Osterholm et al., 1973). Every agent tested modified and minimised the tissue response to trauma, preventing post-traumatic haemorrhagic necrosis. From these findings, the authors postulated that trauma induces an excessive neuronal meta-

* Supported in part by Grant NS IOI74 from the National Institute of Neurological and Communicative Disorders and Stroke. 
bolic response, resulting in release of transmitter substances, particularly norepinephrine. These substances are thought to induce toxic vasospasm, hypoxia and subsequent necrosis of the tissue.

The pathogenic effect of norepinephrine on the traumatised spinal cord as described by Osterholm and Mathews (1972) has not been confirmed in the work of others. Several investigators (see Table I), have failed to find a significant elevation of norepinephrine in spinal cord tissue following trauma in cats, dogs or monkeys (Naftchi et al., I974; Hedeman et al., I974; Rawe et al., I974; de la Torre et al., I974; Bingham et al., I975; Tsubokawa et al., I975; Zivin et al., 1976). De la Torre et al. (1974) did not observe an elevation in norepinephrine levels following a $500 \mathrm{~g}-\mathrm{cm}$ spinal cord contusion. Alpha-methyl tyrosine (AMT), an inhibitor of catecholamine synthesis, did not appear to improve the rate of motor recovery or alter histopathological changes in cats when given 15 mins post-trauma (de la Torre et al., 1974). Naftchi et al. (1974), Hedeman etal. (1974) and Tsubokawa et al.(1975) also failed to find any significant elevation in norepinephrine concentration following experimental spinal cord injury. Schoultz et al. (1976) found a norepinephrine elevation at the trauma site I hour after a $400 \mathrm{~g}-\mathrm{cm}$ contusion of the feline spinal cord. No increase in norepinephrine concentration was noted, however, following experimental injury of adrenalectomised cats. The authors hypothesised that the origin of the elevated spinal cord norepinephrine seen I hour post-trauma was more related to a peripheral adrenal contribution and increased blood levels than to intrinsic cord sources. In a study of catecholamine levels in the spinal cords of monkeys following $300 \mathrm{~g}-\mathrm{cm}$ trauma, Bingham et al. (1975) noted a progressive decrease in norepinephrine levels for 4 hours after trauma. Rawe et al. (1974) reported no increase in norepinephrine levels at the site of impact after a $500 \mathrm{~g}-\mathrm{cm}$ contusion. Despite the efficacy of AMT to reduce norepinephrine to low levels, there was no significant difference in functional neurological recovery after trauma between AMT treated animals and controls (Rawe et al., 1974). In addition, reserpine, a potent anti-norepinephrine agent, produced no significant post-traumatic improvement (Rawe et al., 1974). Alpha-methyl tyrosine was found to increase the rate of motor recovery after experimental spinal cord injury in sheep by Yeo et al. (1975), although there was no significant

\section{TABLE I}

Concentration of catecholamines in the spinal cord after experimental spinal cord trauma*

\begin{tabular}{lllll}
\hline \multicolumn{1}{c}{ Author and year } & Animal & Region & Norepinephrine & Dopamine \\
\hline Osterholm and Mathews (1972) & Cat & Thoracic & Increased & Decreased \\
de la Torre et al. (I974) & Dog, cat & Thoracic & Unchanged & Unchanged \\
Naftchi et al. (I974) & Cat & Thoracic & Unchanged & Increased \\
Hedeman et al. (1974) & Dog, cat & Thoracic & Decreased & Increased \\
Rawe et al. (I974) & Cat & Thoracic & Unchanged & Undetectable \\
Bingham et al. (I975) & Monkey & Thoracic & Decreased & Unchanged \\
Tsubokawa et al. (1975) & Dog & Thoraco- & Unchanged & - \\
Zivin et al. (I976) & Rabbit & Lumbar & Decreased & Unchanged \\
Schoultz et al. (I976) & Cat & Lumbar & Increased & - \\
\hline
\end{tabular}

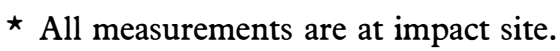


difference in the extent of functional return at the end of 12 weeks. A recent report by Zivin et al. (I976) separately studied post-traumatic monoamine alterations in the contused grey and white matter. Their results showed norepinephrine to be decreased at the impact site in both the grey and white matter.

\section{Dopamine}

Concomitant with norepinephrine studies, another catecholamine, dopamine, has been investigated relative to its possible role in the pathophysiology of spinal cord injury (Osterholm and Mathews, I972; Naftchi et al., I974; Hedeman et al., I974; de la Torre et al., I974; Bingham et al., I975; Zivin et al., I976) (Table I). Osterholm and Mathews (1972) found dopamine to be decreased by a factor of 4 at the site of spinal cord impact within I hour after trauma. Other investigators have noted no significant alteration in dopamine concentration in the contused spinal cord (de la Torre et al., I974; Bingham et al., I975; Zivin et al., I976). But Naftchi et al. (1974) and Hedeman et al. (1974) reported a significant elevation in dopamine concentration following experimental spinal cord injury. The latter authors (Hedeman et al., 1974) also observed that the use of haloperidol, predominantly a dopaminergic blocker, lent a high degree of clinicopathological protection to the injured canine spinal cord, and hypothesised that the traumarelated dopamine elevation may induce intramedullary vasoconstriction through an alpha-adrenergic mechanism which is blocked by this agent. The administration of AMT I 5 mins after injury did not prevent dopamine elevation and afforded no clinical or microscopic protection (Hedeman et al., 1974). The lack of efficacy of AMT may be explained by the early and rapid post-trauma elevation of dopamine which would precede the onset of AMT action (Hedeman et al., 1974). Twenty-four hour pretreatment with AMT, however, suppressed all spinal cord catecholamines, and did prevent trauma-induced dopamine elevation (Hedeman et al., 1974).

\section{Serotonin}

Serotonin, a vasoactive biogenic amine, has been reported increased following central nervous system trauma both experimentally (Osterholm et al., I969; Tsubokawa et al., I975; Zivin et al., 1976) and clinically (Misra et al., 1967) (Table II). Osterholm et al. (I969) demonstrated significant elevation of serotonin in the brain and cerebrospinal fluid (CSF) after experimental cerebral trauma in cats. Elevated serotonin levels were noted in the traumatised canine spinal cord by Tsubokawa et al. (1975), who correlated these levels with the onset of vasoconstriction of the cord vessels and reduced vascular perfusion. Zivin et al. (1976) reported an increase in the white matter serotonin concentration both rostral and caudal to the impact lesion. Other investigators, however, have been unable to confirm serotonin elevation after neural trauma (de la Torre et al., I974; Naftchi et al., 1974; Brodner et al., 1977).

Brodner et al. (1976) have noted a significant decrease in the intramedullary serotonin levels 30 mins after injury, and have also reported a significant rise in CSF serotonin I hour after experimental spinal cord trauma. This elevation in CSF serotonin has been correlated with the appearance of vasoconstriction and reduced perfusion in the intramedullary microcirculation of the contused spinal cord (Brodner et al., I975). The authors postulated that release of serotonin during platelet aggregation and clot lysis in the subarachnoid space following trauma is responsible for the observed vascular changes. 


\section{TABLE II}

Experimental central nervous system trauma: concentration of serotonin in tissue and cerebrospinal fluid*

\begin{tabular}{|c|c|c|c|c|}
\hline \multirow[t]{2}{*}{ Author and year } & \multirow[t]{2}{*}{ Animal } & \multirow[t]{2}{*}{ Region } & \multicolumn{2}{|c|}{ Serotonin } \\
\hline & & & Tissue & CSF \\
\hline Osterholm et al. (1969) & Cat & Brain & Increased $\dagger$ & Increased \\
\hline de la Torre et. al. (1975) & Dog, cat & Thoracic spinal cord & Unchanged & - \\
\hline Naftchi et al. (I974) & Cat & Thoracic spinal cord & Unchanged & \\
\hline Tsubokawa et al. (I975) & Dog & $\begin{array}{l}\text { Thoraco-lumbar } \\
\text { spinal cord }\end{array}$ & Increased & - \\
\hline Brodner et al. (1976) & Cat & Thoracic spinal cord & Unchanged $\ddagger$ & Increased $\S$ \\
\hline Zivin et al. (1976) & Rabbit & Lumbar spinal cord & Increased $\|$ & . \\
\hline
\end{tabular}

* All measurements are at impact site.

$\dagger$ Measurements are from cerebrum and brain stem.

$\ddagger$ No change at 5 min, I 5 min I, 4 and 12 hours post-trauma; decreased ( $p=<0.05)$ at $30 \mathrm{~min}$ after injury.

$\S$ Increased $(\mathrm{p}=<0.025)$ at I hour post trauma.

II Increased in white matter; decreased in grey matter.

Osterholm et al. (1969) have shown that minute quantities of serotonin injected intracerebrally cause severe neurological alterations and cerebral oedema. They hypothesised that, when released from an intracellular site, serotonin acts on other neurons to cause post-traumatic neurological damage. De la Torre et al. (I974) used higher concentrations of serotonin for intracerebral injection of cats and monkeys and found no alteration in either neurological or behavioural parameters.

Serotonin may play an important role in the propagation and development of the spinal cord lesion following trauma. All arguments advanced favouring norepinephrine as a mediator of secondary spinal cord injury could apply equally to serotonin. If pretreatment with reserpine retards damage, serotonin depletion may be an important factor. Howitt and Turnbull (1972) did not find methysergide, a serotonin antagonist, to be effective in lessening the effects of spinal cord injury. Pretreatment with parachlorophenylalanine (PCPA) has been shown by Brodner and Roth (1977) to increase perfusion and improve the microcirculatory dynamics of the traumatised spinal cord. Similarly, Němeček et al. (1975) have reported functional improvement in the experimentally contused rabbit spinal cord after pretreatment with PCPA.

The findings to date do not support the hypothesis that the catecholamines, norepinephrine and dopamine, play a direct and major role in the pathophysiology of spinal cord trauma. Similarly, the place that serotonin may have in this process is unclear. Factors contributing to the inconsistencies in biochemical and histochemical studies of spinal cord injury are the limitations of the models and methods used as well as technical problems with the measurement of biogenic amines. Of concern is the high variability in normal and post-traumatic catecholamine values. Variability is all the more prominent in the traumatised animals because of the lack of standardisation of the spinal cord trauma model using the weight-dropping technique (Dohrmann \& Panjabi, 1976), and the lack of control of the major physiological parameters at the time of injury (Brodner et al., 1976). 


\section{SUMMARY}

The status and function of monoamines in experimental spinal cord trauma remains a subject of controversy and continued debate. The norepinephrine hypothesis has been severely weakened by its lack of reproducibility. Dopamine results are too variable to draw meaningful conclusions. The role of serotonin, particularly with reference to its vasoactive properties and the physiological importance of its effects, remains to be determined.

\section{RÉSUMÉ}

Le rôle et la fonction des monoamines dans les traumatismes expérimentaux de la moelle épinière restent l'objet de controverses et de débats continuels. L'hypothèse de la norépinéphrine a été considérablement affaiblie par son manque de reproductibilité. Les résultats de la dopamine sont trop variables pour permettre de tirer des conclusions valables. Le rôle de la sérotonine, en particulier concernant ses propriétés vasoactives et l'importance physiologique de ses effets, reste à déterminer.

\section{ZUSAMMENFASSUNG}

Der Status und die Funktion von Monoaminen in experimentell verursachten Rückenmarksverletzungen ist umstritten. Die Norepinephrinhypothesis wurde erheblich geschwächt durch den Mangel an Reproduzibilität. Dopamine Resultate sind zu variabel, um gültige Schlüsse zu ermöglichen. Die Rolle von Serotonin bezüglich seiner vasoaktiven Wirkung ist noch zu untersuchen.

\section{REFERENCES}

Bingham, W. G., Ruffolo, R. \& Friedman, S. J. (I975). Catecholamine levels in the injured spinal cord of monkeys. Fournal of Neurosurgery, 42, I74-I 78.

Brodner, R. A., DohrmanN, G. J. \& Roth, R. H. (I977). Intra-medullary serotonin patterns following experimental spinal cord trauma. Mount Sinai fournal of Medicine, 44, 213-2I7.

Brodner, R. A., Dohrmann, G. J., Roth, R. H. \& Rubin, R. A. (I975). Cerebrospinal fluid and spinal cord serotonin: Correlation with intramedullary blood flow patterns in experimental spinal cord trauma. Presented at the European Congress of Neurosurgery, Oxford, England, September, 1975.

Brodner, R. A., DohrmanN, G. J., Roth, R. H. \& Rubin, R. A. (1976). Elevation of 5-hydroxytryptamine in the cerebrospinal fluid following experimental spinal cord injury. Brain Research, I18, 348-35I.

BRoDNER, R. A. \& Roth, R. H. (I977). Effect of parachlorophenylalanine on blood flow in the traumatized cut spinal cord. Presented at the Society for Neuroscience, Anaheim, November, 1977.

Brodner, R. A., vaN Gilder, J. C., Collins, W. F. \& Hamill, B. (I976). Experimental spinal cord trauma: The efficacy of treatment. Presented at the American Association of Neurological Surgeons, San Francisco, April, 1976.

de la Torre, J. C., Johnson, C. M., Harris, L. H., Kajihara, K. \& Mullan, S. (1974). Monoamine changes in experimental head and spinal cord trauma: Failure to confirm previous observations. Surgical Neurology, 2, 5-I I.

Dohrmann, G. J. (1972). Experimental spinal cord trauma. A historical review. Archives of Neurology, 27, 468-473.

Dohrmann, G. J. \& Panjabi, M. M. (1976). Relationship of spinal cord deformation velocity, impulse and energy to lesion volume in 'standardized' spinal cord trauma. Surgical Forum, 27, 466-468.

Hedeman, L. S., Shellenberger, M. K., Gordon, J. H. \& Sil, R. (1974). Studies in experimental spinal cord trauma. Part $\mathrm{r}$ : Alterations in catecholamine levels. Part 2: Comparison of treatment with steroids, low molecular weight dextran, and catecholamine blockade. Fournal of Neurosurgery, 40, 37-5I.

HowitT, W. M. \& TURNBULL, I. M. (1972). Effects of hypothermia and methysergide on recovery from experimental paraplegia. Canadian fournal of Surgery, 15, I79-I86. 
MisRa, S. S., Singh, K. S. \& BhaRgava, K. P. (1967). Estimation of 5-hydroxy-tryptamine $(5-\mathrm{HT})$ level in cerebrospinal fluid of patients with intracranial or spinal lesions. fournal of Neurology, Neurosurgery and Psychiatry, 30, I63-165.

Naftchi, N. E., Demeny, M., DeCrescito, V., Tomasula, J. J., Flamm, E. S. \& Campbell, J. B. (1974). Biogenic amine concentrations in traumatized spinal cords of cats. Effect of drug therapy. Fournal of Neurosurgery, 40, 52-57.

Němeček, S., Petr, R., Rozsival, V., Suba, P. \& Melka, D. (1975). Effects of drug therapy on experimental spinal cord trauma. Proceedings of the Internation Congress of Neuropathology. Excerpta Medica, pp. 659-662.

Osterholm, J. L. (I974). The pathophysiological response to spinal cord injury. The current status of related research. Fournal of Neurosurgery, 40, 3-33.

Osterholm, J. L., Bell, J., Meyer, R. \& Pyenson, J. (I969). Experimental effects of free serotonin on the brain and its relation to brain injury. Part I: The neurological consequences of intracerebral serotonin injections. Part 2: Trauma-induced alterations in spinal fluid and brain. Part 3: Serotonin-induced cerebral edema. Fournal of Neurosurgery, 3I, 408-42I.

OSteRHOLM, J. L. \& MATHEWS, G. J. (1972). Altered norepinephrine metabolism following experimental spinal cord injury. Part $\mathrm{I}$ : Relationship to hemorrhagic necrosis and post-wounding neurological deficits. Part 2: Protection against traumatic spinal cord hemorrhagic necrosis by norepinephrine synthesis blockade with alpha methyl tyrosine. Fournal of Neurosurgery, 36, 386-40I.

Osterholm, J. L., Mathews, G. J., Irvin, J. D. \& Calisnick, B. (1973). Antinorepinephrine therapy against traumatic hemorrhagic necrosis of the spinal cord: Preliminary report. Clinical Neurosurgery, 20, 382-399.

Rawe, S. E., Roth, R. H., D’Angelo, C. M., Biber, M. C. \& Collins, W. F. (1974). Norepinephrine levels in experimental spinal cord trauma. Presented at the American Association of Neurological Surgeons, Saint Louis, April, I974.

Schoultz, T. W., Deluca, D. C. \& Reding, D. L. (I976). Norepinephrine levels in traumatized spinal cord of catecholamine-depleted cats. Brain Research, 109, 367-374.

Tsubokawa, T., Nakamura, S., Hayashi, N., Taguma, N., Sugawara, T., Coto, T. \& MORIYASU, N. (1975). The circulatory disturbance of spinal cord injury and its response to local cooling therapy. Neurologia Medico-chirurgica, 15, 87-93.

Yeo, J. D., PAyne, W. \& Hinwood, B. (I975). The experimental contusion injury of the spinal cord in sheep. Paraplegia, 12, 275-296.

Zivin, J. A., Doppman, J. L., Reid, J. L., Tappaz, M. L., SaAvedra, J. M., Kopin, I. J. \& JACOBowitz, D. M. (I976). Biochemical and histochemical studies of biogenic amines in spinal cord trauma. Neurology, 26, 99-107. 